\title{
A look at the two-way referral system: experience and perception of its handling by medical consultants/specialists among private medical practitioners in Nigeria
}

\begin{abstract}
Background: A two-way referral system is an organized two-way relationship between a health care provider or physician in a health care facility at one level of the health care system and another health care provider or physician in a health care facility at the same or higher level of the health care system. In a two-way referral system, there ought to be effective communication between physicians at the same or different levels of the health care system. It is obligatory for the referring physician to refer a patient promptly, in a manner that guarantees efficient, cost-effective, optimal and quality care for the patient. It also requires the physician in the receiving hospital/ health care facility to refer the patient back after treatment, to the health care facility or physician that initiated the referral in the first instance, with clear feedback on the observed findings, investigations conducted for the patient and the treatment given to the patient. This aids effective continuity of care and also updates the referring physician's knowledge. Since an effective, efficient and integrated referral system is vital to the performance of Nigeria's healthcare system, the importance of the practice and perception of the two-way referral system by Private Medical Practitioners in Nigeria, particularly as it affects their relationship with Medical Consultants/ Specialists cannot be over-emphasized.
\end{abstract}

Objective: This study assessed the practice and perception of the two-way referral system by Private Medical Practitioners in Nigeria, with the hope of providing valuable information that will help improve the practice of the two-way referral system in Nigeria, particularly through an enhanced relationship between Private Medical Practitioners in Nigeria and Medical Consultants/Specialists.

Methods: This was a cross-sectional survey of Private Medical Practitioners in Nigeria to assess their self-reported practice and perception of the two-way referral system. Data were analysed using the Statistical Package of Social Sciences version 16 (IBM SPSS, Chicago, IL) statistical software, with Pearson's chi square used to determine associations between variables. Statistical significance was set at a $\mathrm{P}$ value of $<0.05$.

Results: There were 118 respondents with 112 males and 6 females (M:F=1:0.05). The age range of the respondents was $33-71 \mathrm{yrs}$, with a mean age of $58.67 \pm 7.06 \mathrm{yrs}$. Majority of the respondents $(92.4 \%)$ had practiced for more than $20 \mathrm{yrs}$, while majority $(98.3 \%)$ practiced in only a private health facility. Only $4.2 \%$ of the respondents claimed not to be aware of the two-way referral system, while $50 \%$ were extremely aware. Most (89.7\%) of the respondents had good knowledge of the two-way referral system. $44.4 \%$ of the respondents claimed they have never received a backward referral letter or feedback from medical consultants/specialists after referral of patients to them, while $12.0 \%$ claimed to have received sometimes. Out of those who reported they got feedback, less than one third (29.9\%) got a feedback only when they requested for it. Though more than half $(54.7 \%)$ of the respondents were not at all satisfied with the handling of referrals by Medical Consultants/Specialists in Tertiary/ Teaching Hospitals and almost half $(48.7 \%)$ rated the handling of referrals by Medical Consultants/Specialists to be poor, majority (83.9\%) strongly agreed that the two-way referral system is relevant to the health care delivery system.

Conclusion: The two-way referral system has the potential to significantly strengthen Nigeria's healthcare system through effective participation and synergy between Private Medical Practitioners and Medical Consultants/Specialists. Although Private Medical Practitioners in Nigeria may have good awareness and knowledge of the Twoway referral system, their experience and perception of the handling of referrals by Medical Consultants/Specialists is poor.

Keywords: two-way referral system, private medical practitioners, medical consultants, care provider
Volume 2 Issue 3 - 2018

\section{Enabulele O,' Enabulele JE²}

'Department of Family Medicine, University of Benin Teaching Hospital, Nigeria

${ }^{2}$ Department of Restorative Dentistry, University of Benin, Nigeria

Correspondence: Enabulele O, Department of Family Medicine, University of Benin Teaching Hospital, c/o P.O.Box 10427, Ugbowo, Benin City, Edo State, Nigeria, Email emien.enabulele@uniben.edu t

Received: March 01, 2018| Published: May 16, 2018 
Abbreviations: GPs, general practitioners; AGPMPN, association of general and private medical practitioners of Nigeria; SOFPON, society of family physicians of Nigeria; NUC, national universities commission;

\section{Introduction}

A referral is defined as a process in which a health care provider at one level of the health care system, having insufficient resources (such as equipment, skills and knowledge) to manage a clinical condition, seeks the assistance of a better resourced health care facility or health care provider at the same or higher level of the health care system, to assist in or take over the management of the client's case. ${ }^{1}$ Similarly, a two-way referral system is an organized two-way relationship between a health care provider or physician in a health care facility at one level of the health care system and another health care provider or physician in a health care facility at the same or higher level of the health care system. ${ }^{2}$ In a two-way referral system, there is effective communication between physicians at the same or different levels of the health care system. The two-way referral system makes it obligatory for the referring physician to refer a patient promptly, in a manner that guarantees efficient, cost-effective, optimal and quality care for the patient. It also requires the physician in the receiving hospital/health care facility to refer back the patient after treatment, to the health care facility or physician that initiated the referral in the first instance, with clear feedback on the observed findings, investigations conducted for the patient and the treatment given to the patient. ${ }^{2}$ This aids effective continuity of care and also updates the referring physician's knowledge. A well-functioning referral system can lower cost and enhance equity. ${ }^{3}$ Indeed; it is globally acknowledged that an effective referral system plays a key role in directing the distribution of patients, standardizing medical care procedure, controlling rising medical cost and maintaining the continuity, coordination and integration of medical care. ${ }^{2}$

It has also been asserted that communication between General practitioners (GPs), Family Physicians and other Specialists is important, if patients are to receive the right type of care at the right time/moment. ${ }^{4,5}$ Nigeria's National Health System is made up of both public and private healthcare systems, and consist of three levels of care, namely: Primary, Secondary and Tertiary levels of care. ${ }^{6}$ Amongst several factors that determine its performance is an effective referral system between the three levels of care, either within the public or private healthcare system or between the private and public healthcare system. ${ }^{7}$ Over $60 \%$ of the healthcare services offered to Nigerians is said to be delivered by the private healthcare sector. ${ }^{8}$ Referrals to other specialists and subspecialists by the Primary Care Physicians including Private Medical Practitioners are most times based on a realistic appreciation of their limitations. ${ }^{9}$ This ensures optimal, cost effective and quality care for the patients. Since an effective, efficient and integrated referral system is vital to the performance of Nigeria's healthcare system, the importance of the practice and perception of the two-way referral system by Private Medical Practitioners in Nigeria, particularly as it affects their relationship with Medical Consultants/ Specialists cannot be over-emphasized. Though available information suggest that studies may not have been previously conducted to assess the practice and perception of the two-way referral system by Private Medical Practitioners in Nigeria, a casual interaction with them (including remarks made at their organizational meetings and conferences) indicate that these healthcare providers may be generally unhappy with their relationship with Medical Consultants/Specialists, as it concerns the practice of the two-way referral system. This study was therefore aimed at evaluating the practice and perception of the two-way referral system by Private Medical Practitioners in Nigeria as well as assess the experience and perception of handling of referrals by medical consultants/specialist by private medical practitioners in Nigeria, with the hope that its outcome will provide valuable information that will assist Government, Health authorities and other stakeholders in any effort aimed at improving the practice of the twoway referral system in Nigeria, particularly through an enhanced relationship between Private Medical Practitioners in Nigeria and Medical Consultants/Specialists.

\section{Materials and methods}

This was a descriptive cross sectional study conducted during the Annual National conference organized by the Association of General and Private Medical Practitioners of Nigeria (AGPMPN) in March 2017 in Osogbo, Osun State of Nigeria. AGPMPN is the umbrella body of all private medical and dental practitioners in Nigeria with the core objective of catering for the welfare of its members, encouragement of continuing medical education and promotion of professional excellence amongst its members, in order to improve and sustain quality health care services to the beneficiaries. It has branches in the 36 states of Nigeria and the Federal Capital Territory, Abuja, and organizes on a yearly basis an Annual General and Scientific conference where General and Private medical and dental practitioners from all parts of Nigeria are provided the opportunity to deliberate on several issues and policies bothering on their professional and organizational advancement as well as the state of Nigeria's healthcare system. ${ }^{10}$

The study population consisted of private medical practitioners in attendance at the AGPMPN conference, with the theme: "Metabolic Syndrome: The rising scourge and implication on Public health". Only consenting General and Private medical and dental practitioners were recruited for the study. To make the study reliable the sample size was determined using the following formula ${ }^{11}$

$$
\frac{n=1.96^{2} \times p(1-p)}{0.05^{2}}
$$

A Nigerian study ${ }^{12}$ reported a prevalence of $7.1 \%$ among new patients presenting at a tertiary hospital with written referral letters and this was used as $\mathrm{P}$ and marginal error of $5 \%$ with $95 \%$ confidence level. The calculated sample size was 99.9 which were approximated to 100 . An attrition rate of $10 \%$ was incorporated giving the minimum sample size of 110 . The data collection instrument was a pre-tested self-administered questionnaire which consisted of sections on: Socio-demographics (Gender, Age, place of practice, Religion, Marital status, Cadre, Length of practice in occupation), Practice and Perception of the Two-way referral system. Seven questions assessed respondents' practice of the two-way referral system. Six questions sought to determine their perception of the two-way referral system. Of the six questions four had Likert scale responses. ${ }^{13}$ Perception in this case, was defined as their opinions or beliefs about the operation of the two-way referral system. For the purpose of statistical analysis, the 5 point Likert scale responses were modified to three, with Agree scored 3, Disagree 2, and Don't know 1. Data entry and analysis was done using the Statistical Package of Social Sciences version 16 (IBM SPSS, Chicago, IL) statistical software. Descriptive statistics in the 
form of frequency, mean, standard deviation, and cross-tabulation were done. Pearson's chi square was used to determine associations between variables while statistical significance was set at a $P$ value of $<0.05$. Statements, tables, figures and cross tabulations were used to report the results.

\section{Results}

A total of 150 questionnaires were administered. 130 were returned, giving a response rate of $86.7 \%$. The returned questionnaires were screened for completeness with twelve (12) of the returned questionnaires not properly filled. Hence, 118 questionnaires were utilized in the study. The age range of respondents was 33-71yrs, with a mean age of $58.67 \pm 7.06 \mathrm{yrs}$. There was a male preponderance with males accounting for $94.9 \%$ (112) of the respondents and a male: female ratio of 1:0.05. Less than half (46.6\%) of the respondents were Yoruba, while Ibos and other minority ethnic groups accounted for $26.3 \%$ each of the respondents. The least represented major ethnic group was Hausa $(0.8 \%)$. Majority $(88.1 \%)$ of the respondents were Christians, and most of them (86.4\%) were married (Table 1). Majority of the respondents $(92.4 \%)$ had practiced for more than 20yrs (Figure 1), with $99.2 \%$ of the respondents having Bachelor of Medicine and Bachelor of Surgery (MBBS) as basic medical qualification. Majority $(98.3 \%)$ of the respondents practiced in only a private health facility. Figure 2 depicts the distribution of the facility type in which the respondents practiced. Hospitals accounted for $60.2 \%$, while Clinics accounted for $11.9 \%$.Only $4.2 \%$ of the respondents claimed not to be aware of the two-way referral system, while $50 \%$ were extremely aware. Figure 3 various sources of awareness of the two-way referral system were reported by the respondents. AGPMPN was reported as a source of awareness by $47.8 \%$ of those who were aware. Workshops and seminars accounted for $44.2 \%$, while undergraduate training accounted for $13.6 \%$. The least reported sources were radio news/ jingles $(0.9 \%)$, television news $(0.9 \%)$, National Association of Government General Medical and Dental Practitioners (NAGGMDP) $(2.7 \%)$, Social media $(2.7 \%)$ and Internet $(2.7 \%)$. Obtaining information regarding the two-way referral system from colleagues was reported by $27.4 \%$ of those who were aware. The Nigerian Medical Association (NMA) as a source of awareness was reported by $24.8 \%$, Society of Family Physicians of Nigeria (SOFPON) (12.4\%), Textbooks (15.0\%) and Journals (11.5\%).

Most (89.7\%) of the respondents correctly stated that the referral process could only be said to have been completed when a backward referral letter is sent by the receiving Medical Consultant/Specialist and received by the Physician who primarily referred the patient. Majority of the respondents $(83.9 \%)$ strongly agreed that the twoway referral system is relevant to the healthcare delivery system, with $98.3 \%$ of the respondents believing in the operation of the two-way referral system. Half $(50 \%)$ of those who did not believe in the operation of the two-way referral system were of the opinion that the two-way referral system is not practicable, while the other half claimed that Medical Consultants/Specialists hijack the process. Almost all (99.2\%) of the respondents refer patients to Medical Consultants/Specialists, with $74.4 \%$ referring patients to both Private and Public Health care facilities. Only a few (5.1\%) rarely refer patients to Medical Consultants/Specialists, while $47.9 \%$ and $38.5 \%$ refer patients sometimes and often, respectively. With regard to transmission of a backward referral letter or feedback from Medical Consultants/Specialists, $44.4 \%$ of the respondents claimed they have never received a backward referral letter or feedback, while $12.0 \%$ claimed to have received sometimes. Figure 4 illustrates the period within which a feedback is gotten across to the referring Physician. Less than one third (29.9\%) of the respondents reported that they got a feedback only when they requested for it. However $8.5 \%$ claimed they got a feedback immediately after the receiving Medical Consultant/ Specialist finished treating the referred patient, while $44.9 \%$ claimed they never got any feedback. More than half (54.7\%) of the respondents were not at all satisfied with the handling of referrals by Medical Consultants/Specialists in Tertiary/ Teaching Hospitals, while only $0.9 \%$ were extremely satisfied. Almost half (48.7\%) of the respondents rated the handling of referrals by Medical Consultants/ Specialists in Tertiary/Teaching Hospitals to be poor while $22.2 \%$ and $20.5 \%$ of the respondents respectively rated the handling of referrals to be fair and good (Table 2). More than half (52.9\%) of those who rarely received feedback and $65.4 \%$ of those who never received feedback felt that the manner of handling of referrals by Medical Consultants/Specialists had not positively impacted on their attitude and practice of the two-way referral system and this was statistically significant (Table 3). Majority (76.6\%) of the respondents who felt that their attitude and practice of the two-way referral system had not been positively impacted upon by the handling of referrals by medical consultants/specialists were not satisfied with the handling of referrals by medical consultants/specialists and this was statistically significant (Table 4).

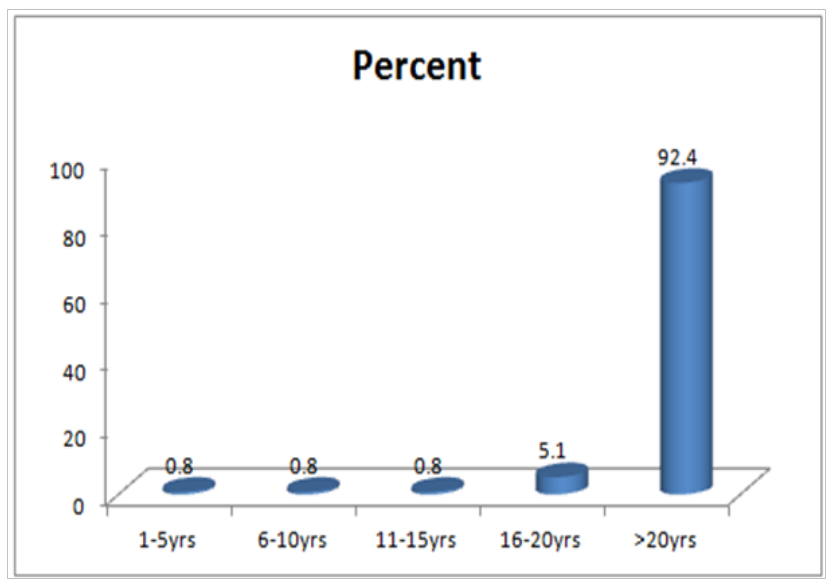

Figure 1 Length of Practice as a Doctor. 
Table 1 Socio-Demographic characteristics of the Respondents

\begin{tabular}{|c|c|c|}
\hline Characteristics & Frequency & $\%$ \\
\hline \multicolumn{3}{|l|}{ Gender } \\
\hline Male & 112 & 94.9 \\
\hline Female & 6 & 5.1 \\
\hline \multicolumn{3}{|l|}{ Ethnic group } \\
\hline Ibo & 31 & 26.3 \\
\hline Hausa & 1 & 0.8 \\
\hline Yoruba & 55 & 46.6 \\
\hline Others & 31 & 26.3 \\
\hline \multicolumn{3}{|l|}{ Religion } \\
\hline Christianity & 104 & 88.1 \\
\hline Islam & 13 & 11 \\
\hline Others & 1 & 0.8 \\
\hline \multicolumn{3}{|l|}{ Marital Status } \\
\hline Single & 11 & 9.3 \\
\hline Married & 102 & 86.4 \\
\hline Separated & 3 & 2.5 \\
\hline Widow & 2 & 1.7 \\
\hline Total & 118 & 100 \\
\hline
\end{tabular}

Table 2 Respondents' Satisfaction and Rating of the handling of referrals by Medical Consultants/Specialists in Teaching/Tertiary Hospitals

\begin{tabular}{|c|c|c|}
\hline Characteristic & Frequency & $\%$ \\
\hline \multicolumn{3}{|l|}{ Satisfaction } \\
\hline Extremely satisfied & 1 & 0.9 \\
\hline Very satisfied & 13 & 11.1 \\
\hline Moderately satisfied & 25 & 21.4 \\
\hline Slightly satisfied & 14 & 12 \\
\hline Not at all satisfied & 64 & 54.7 \\
\hline \multicolumn{3}{|l|}{ Rating } \\
\hline Excellent & 1 & 0.9 \\
\hline Very good & 9 & 7.7 \\
\hline Good & 24 & 20.5 \\
\hline Fair & 26 & 22.2 \\
\hline Poor & 57 & 48.7 \\
\hline Total & 117 & $100 \%$ \\
\hline
\end{tabular}

One Respondent claimed not to refer patients to Medical Consultants/ Specialists hence the total for this table is less than the sample.
Table 3 Impact of handling of referrals by Medical Consultants/Specialists on Respondents' attitude and practice of the two-way referral system

\begin{tabular}{|c|c|c|c|c|}
\hline Characteristic & $\begin{array}{l}\text { Agree } \\
\text { N (\%) }\end{array}$ & $\begin{array}{l}\text { Undecided } \\
\text { N (\%) }\end{array}$ & $\begin{array}{c}\text { Disagree } \\
\text { N }(\%)\end{array}$ & $\begin{array}{l}\text { Total N } \\
(\%)\end{array}$ \\
\hline Sometimes & $10(71.4)$ & $1(7.1)$ & $3(21.4)$ & $14(100.0)$ \\
\hline Rarely & $16(31.4)$ & $8(15.7)$ & $27(52.9)$ & $51(100.0)$ \\
\hline Never & $11(21.2)$ & $7(13.5)$ & $34(65.4)$ & $52(100.0)$ \\
\hline Total & $37(31.6)$ & $16(13.7)$ & $64(54.7)$ & $117(100.0)$ \\
\hline
\end{tabular}

Table 4 Respondents' Satisfaction and Impact of handling of referrals by Medical Consultants/Specialists

\begin{tabular}{lcll}
\hline Characteristic & $\begin{array}{c}\text { Satisfied } \\
\mathbf{n}(\%)\end{array}$ & $\begin{array}{l}\text { Not Satisfied } \\
\mathbf{n}(\mathbf{\%})\end{array}$ & $\begin{array}{l}\text { Total } \\
\mathbf{n}(\%)\end{array}$ \\
\hline Positive impact & $27(73.0)$ & $10(27.0)$ & $37(100.0)$ \\
Undecided & $11(68.8)$ & $5(31.2)$ & $16(100.0)$ \\
No impact & $15(23.4)$ & $49(76.6)$ & $64(100.0)$ \\
Total & $53(45.3)$ & $64(54.7)$ & $117(100.0)$ \\
\hline
\end{tabular}

$\mathrm{P}<0.0001$

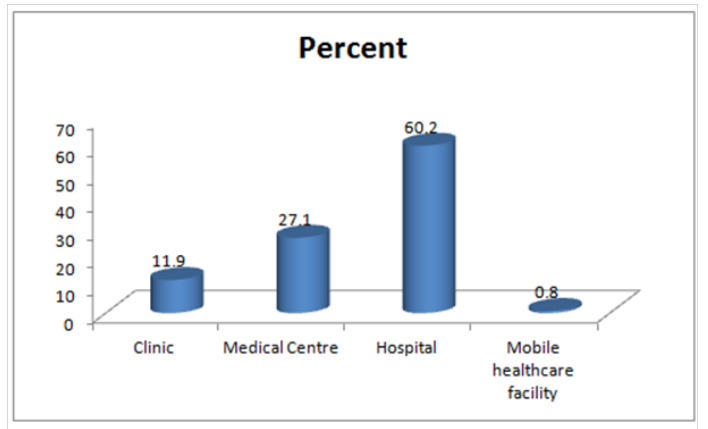

Figure 2 Type of Facility

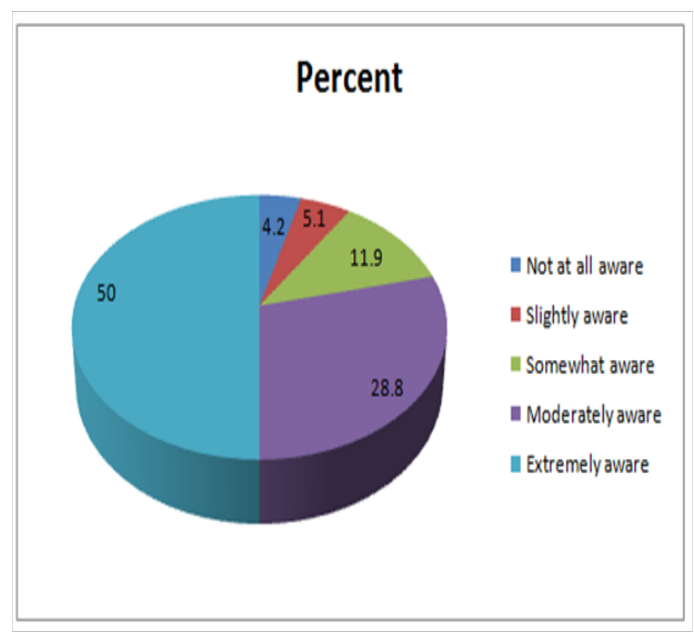

Figure 3 Level of Awareness of the Two-way Referral System. 


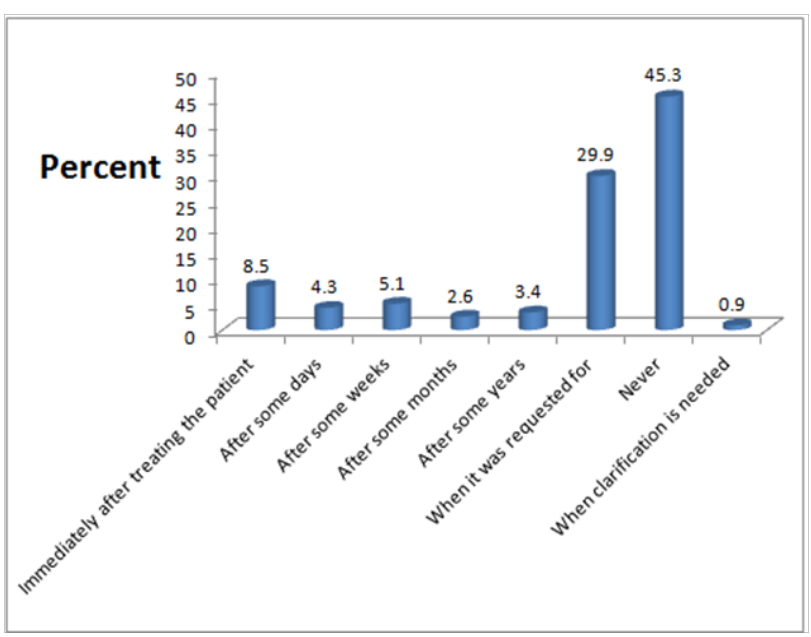

Figure 4 Period within which a feedback was gotten across to the referring Physician.

\section{Discussion}

Nigeria is a multi-ethnic country with three major ethnic groups (Ibo, Yoruba and Hausa) and several minority ethnic groups. ${ }^{14}$ The three major ethnic groups were represented in this study with the Yorubas being in the majority. This may have been due to the fact that the AGPMPN conference held in Osogbo, Osun State (one of the States in the South-West geo-political zone) which is largely populated by the Yorubas. Hence, for reason of the close proximity of the conference venue to the South-West States of Nigeria, more members of AGPMPN who were of the Yoruba ethnic group were more likely to participate in the conference. Nigeria is dominated by two main religions, Christianity and Islam. ${ }^{14}$ In this study, Christians were predominant, most likely due to the fact that since the conference held in the southern part of Nigeria which is populated more by Christians compared to the northern part of Nigeria populated more by Muslims, ${ }^{14}$ more members of AGPMPN who were Christians were more likely to participate in the conference. It is not surprising that majority of the respondents practiced in a private health facility. This is on account of the fact that the respondents surveyed were Private medical practitioners, $99.2 \%$ of whom had only a basic medical qualification (MBBS) and who belonged to the Association of General and Private Medical Practitioners of Nigeria (AGPMPN). Undergraduate training was observed as a source of awareness for only a few of the respondents indicating that the undergraduate medical curriculum may have to be reviewed with a view to creating better opportunity for teaching undergraduate medical and dental students about the two-way referral system. Perhaps, the on-going efforts by the National Universities Commission (NUC) to establish departments of family medicine in Nigerian Universities ${ }^{15}$ with integration of family medicine courses in the undergraduate medical curriculum may help to promote awareness of the two-way referral system during the period of undergraduate medical and dental training.

This is particularly as it pertains to the two-way referral system in primary medical care. The two-way referral system involves a relationship between one health care provider/physician and another. Private medical practitioners who are responsible for the healthcare needs of more than half of Nigeria's population ${ }^{8}$ may have need to refer a patient to another physician/specialist or to another level of the healthcare system. For this relationship to produce the desired effect there must be a good understanding of the tenets of such a two-way relationship. Furthermore, it is imperative that referring physicians understand the point at which the referral process is said to have been completed. It is therefore noteworthy that majority of the respondents in this study had some level of awareness about the tenets of the twoway referral system and majority also correctly stated the point at which the referral process is said to have been completed. This may be an indication that the respondents rightly understand the various aspects of the referral process. This is very significant and presents a good opportunity in any future effort by policy makers and managers of the Nigerian health system to strengthen the two-way referral system, similar to efforts by countries like Ghana in formulating a referral policy and guidelines to strengthen the two-way referral system. ${ }^{16}$ It has been reported that the referral process is good and would improve health care if properly implemented. ${ }^{17}$ This was also the assertion and belief of the respondents in this study, as majority of them were not only of the opinion that the two-way referral system is relevant to the health care delivery system, but also believed in the operation of the two- way referral system. This may have influenced the practice of the respondents as this study found out that most of them referred patients to medical and dental consultants/specialists. In spite of the merits associated with the two-way referral system, it has been observed that its implementation has not met the desired expectations, especially with regard to backward referral ${ }^{18}$ with lack of feedback hindering the referral process. ${ }^{17}$

This was also observed in this study as almost all of the respondents claimed that they referred patients to medical and dental consultants/ specialists, with only a few receiving a feedback/backward referral letter from the medical or dental consultants/specialists after they had managed the referred patient. This is quite worrisome, particularly as the healthcare system in Nigeria is a three-tier system ${ }^{6}$ and referrals are expected to be done between these tiers. This kind of relationship is not progressive and detracts from the objectives of the two-way referral system, particularly with regard to creation of opportunities for improved learning for medical and dental practitioners at either end of the referral spectrum, as well as the important objective of improved patient care. ${ }^{9-19}$ There is need to evaluate the reasons for the poor backward referral in Nigeria. A major feature of the twoway referral system is effective and rich knowledge sharing. Without a feedback or backward referral it would merely amount to handing over of patients from one physician to another, thus contravening the principles of patient-centred health care. ${ }^{20,21}$ It is imperative that both the referring physician and the Medical Consultant/Specialist (to whom patients are usually referred) recognise the fact that referral is bi-directional. ${ }^{22}$ Therefore, the referring physician does not need to request for feedback or backward referral as observed in this study before it is given. It is of paramount importance that physicians communicate and share knowledge with each other to look after patient's healthcare needs in the two-way referral system. ${ }^{23,24}$ This may be why the respondents in this study were not satisfied with the handling of referrals by medical and dental consultants/specialists in Tertiary/Teaching Hospitals as they rarely get feedback or backward referrals from the specialists. The two-way referral system is expected not only to create an efficient and seamless pathway to transfer patients to the most suitable specialists and facilities in a timely manner but also to act as an effective knowledge sharing channel between the referring physician and the specialists ${ }^{25}$ with possible positive impact on their 
attitude and practice of the two-way referral system. However, this was not the case in this study, giving the relatively poor satisfaction of the respondents with the way specialists handle referrals sent to them. This latter finding is equally disturbing and a cause for concern by all stakeholders in the Nigerian health sector, particularly bearing in mind the impact of the current dislocated 3-tier system of health care in Nigeria ${ }^{7}$ on the overall rating and performance of the Nigerian health system. The findings of this study would therefore be relevant in any concerted effort at re-organizing Nigeria's currently fractured and dislocated National Health System ${ }^{7}$ predicated on an effective and efficient primary health care system ${ }^{6}$ and a robust referral system.

\section{Conclusion}

The two-way referral system has the potential to significantly strengthen Nigeria's health system through effective participation and synergy between Private Medical Practitioners and Medical Consultants/Specialists. Although Private Medical Practitioners in Nigeria may have good awareness and knowledge of the two-way referral system, their experience and perception of the handling of referrals by Medical and Dental Consultants/Specialists is poor.

\section{Recommendations}

This study recommends further researches into the operation of the two-way referral system at all levels of Nigeria's health care system, particularly at institutional levels. This study identifies the need to improve the awareness and understanding of the two-way referral system during the period of undergraduate medical and dental training. In this regard, it will be beneficial to encourage Nigerian Universities to establish Departments of Family Medicine as advised by the National Universities Commission (NUC). This will aid the effective and practical delivery of appropriate lectures on the two-way referral system by Family Physicians who are frontline doctors directly involved in primary medical care. This study also recommends dynamic and regular reviews of the operation of the two-way referral system in Nigeria to help track the performance and outcome indicators of the two-way referral system, with the overall aim of strengthening Nigeria's National Health System. Finally, the convocation of joint sessions of members of Private practitioners, Family Physicians and other Medical Consultants/Specialists, is recommended. This will aid mutual understanding between the various groups of medical practitioners, and also enhance knowledge sharing and learning.

\section{Limitations of the study}

The non-availability of a previous Nigerian study on the subject matter limited the comparative analysis of the study results. Furthermore, the sample utilized in this study may not be truly representative of the general population of general and private medical and dental practitioners in Nigeria, particularly as it was conducted only amongst private medical practitioners who participated in the annual conference organized by the Association of General and Private Medical Practitioners of Nigeria (AGPMPN), the umbrella body of all private medical practitioners in Nigeria. Finally, the characteristics of the respondents who were largely drawn from the southern part of Nigeria (for reasons earlier advanced) could have affected some of the study findings, even though this may be mitigated by the fact that the branch leaderships of the AGPMPN from all parts of Nigeria seem to have participated in the conference (from where the respondents were surveyed). Further researches, particularly institution based researches, on the operation of the two-way referral system in Nigeria, are therefore recommended to address the observed limitations.

\section{Acknowledgements}

None.

\section{Conflict of interest}

The authors declare there is no conflict of interest.

\section{References}

1. Cervantes K, Salgado R, Choi M, et al. Rapid Assessment of Referral Care Systems: A Guide for Program Managers. The Basic Support for Institutionalizing Child Survival Project (BASICS II) for the United States Agency for International Development. Arlington, Virginia; 2016: p. 93.

2. Ren JP, Guo O, Xu W. A study on present situation of two-way referral of community health service in Hangzhou City. Zhejiang Province of China. J Hangzhou Teach Coll. 2007; p. 392-395.

3. Gerdtham UG, Johnson B. International comparisons of health expenditure: theory, data and economic analysis. In: New-house JP, et al editors. Handbook of Health Economics. Chapter 1. Amsterdam. The Netherlands: Elsevier; 2000. p. 11-53.

4. Berendsen AJ, Kuiken A, Benneker WH. How do general practitioners and specialists value their mutual communication? A survey. BMC Health Services Res. 2009;9:143.

5. McPhee SJ, Lo B, Saika GY, et al. How good is communication between primary care physicians and sub-specialty Consultants? (Special Report). Arch Intern Med. 1984;144:1265.

6. Federal Ministry of Health. The National Health Policy and Strategy to Achieve Health for All Nigerians, Lagos: Federal Ministry of Health; 1988.

7. Enabulele O. The Nigerian Health Sector: Burning Issues and the Way Forward. Keynote address delivered at the opening ceremony of the 2015 Annual General Meeting and Scientific Conference of Edo State branch of Nigerian Medical Association. Benin City; Nigeria, 2015.

8. Federal Ministry of Health in Nigeria at 50: Championing half a century of sustainable health development. Abuja: Federal Ministry of Health; 2010.

9. Rakel RE. Special problems in tertiary care settings: Referrals. In: Rakel RE, editor. Textbook of Family Practice. 6th ed. Philadelphia: Saunders; 2002, p.151-152.

10. Association of General and Private Medical Practitioners of Nigeria (AGPMPN). About Us. History of AGPMPN; 2017.

11. Araoye MO. Research methodology with statistics for health and social sciences. Ilorin, Nigeria: Nathadex publishers; 2004. p. 112-119.

12. Akande TM. Referral system in Nigeria: study of a tertiary health facility. Ann Afric Med. 2004;3:130-133.

13. Vagias, Wade M. Likert-type scale response anchors. Clemson International Institute for Tourism and Research Development, Department of Parks, Recreation and Tourism Management. Clemson University; 2006.

14. Federal Republic of Nigeria. Nigerian culture and heritage.

15. National Universities Commission. NUC, Stakeholders discuss new $M B B S-B M A S$. Monday Bulletin; a publication of the office of the Executive Secretary, 2015. p 3-5.

16. Ghana Ministry of Health referral policy and guidelines. 2017. p. 26. 
17. Eskandari M, Abbaszadeh A, Borhani F. Barriers to referral system to health care provision in rural societies in Iran. J Caring Sci 2013;2:229236

18. Wenya Y, Meina L, Xin N, et al. Practices and attitudes of doctors and patients to downward referral in Shanghai, China. Br Med J Open. $2017 ; 7 \mathrm{e} 012565$

19. Juan D, Xiaoqin L, Yadong W. Mutual referral: a survey of GPs in Beijing. Family Practice. 2012:29(4):441-447.

20. Xie M, Xie G, Zhang Y. Construction of regional medical service mode of co-operation. Modern Hosp Mgt. 2011;42:18-20.

21. Zhou L, Nunes M. Identifying knowledge sharing barriers in the collaboration of traditional and western medicine professionals in Chinese
Hospitals: A case study. J Librarianship Info Sci. 2012;44(4):238-248.

22. Jarallah JS. Referral from primary care to hospitals in Saudi Arabia: Quality of referral letters and feedback reports. J Fam Community Med. 1998;5(2):15-22.

23. Steward M. Towards a global definition of patient centred care: The patient should be the judge of patient centred care. Br Med J. 2001;322(7284):444446 .

24. Maizes V, Rakel D, Niemiec C. Integrative medicine and patient centred care. J Sci Healing. 2009;5:277-289.

25. Yuan B. Referral anxiety. China Health Human Res. 2012;5:29-31. 